\title{
Drug and Alcohol Abuse Prevention Education in Selected Secondary Schools in Zambia: Current Practices
}

\author{
Isaac Masiye, Daniel Ndhlovu
}

\author{
University of Zambia, School of Education, P.O. Box 32379, Lusaka. Zambia
}

\begin{abstract}
The study sought to establish practices in drug and alcohol abuse prevention education in selected secondary schools in Zambia. This article is an extract from one of the objectives of the study. The background of the study emanates from the fact that despite escalating incidences of drug and alcohol abuse among schoolgoing children, little was known concerning prevention practices in Zambia's secondary schools. The study adopted a descriptive survey research design to collect, analyze and interpret both quantitative and qualitative data from 514 respondents. The study found that learners were taught more of factual information than skillbased and normative education, schools used external prevention education providers, peer educators and involved parents in prevention service provision. Other practices included evaluation of prevention education activities through role plays, class exercise and question and answer sessions, and prevention education was targeted at all leaners in the school.On the basis of the study findings it is recommended that providers of preventive education should teach content that has the potential to reduce abuse by learners in the school such as drug refusal skills in combination with social life skills training.
\end{abstract}

Keywords: Drug abuse, Alcohol abuse, Prevention education practices, Secondary schools

\section{INTRODUCTION}

\subsection{Back Ground}

Zambia is facing a rapidly growing drug and alcohol abuse situation among young people (DEC, 2012).The consequences of abuse of these substances are so immense that they impact negatively on the learners' educational experiences and management of schools. For instance, learners who abuse drugs tend to care less about their academic work. They tend to display problem behaviours in school such as truancy, bullying, disrespecting teachers and absenteeism. The overwhelming negative consequences of drug and alcohol abuse on learners in schools highlight the urgency and the need for effective prevention interventions. Since mid-1990s, drug and alcohol abuse prevention interventions have been intensified in schools in Zambia. This is in terms of aggregate level of prevention activities, the number of organizations involved, and government's will to fight drug and alcohol abuse in the country. This has been done with the conviction that they can bring about increased knowledge, antidrug attitudes and behaviour change among learners. However, despite these efforts, the number of learners reported to have been abusing drugs and alcohol has steadily been increasing. For instance, in 2013 the Drug Enforcement Commission, a government agency that deals with drug prevention and control in the country, through its Education and Counselling Department, counselled 159 learners out of 288 persons attended to for drug abuse related problems, while 176 learners out of 302 persons were counselled in 2014 (DEC, 2014). This represented a substantial increase in the number of learners involved in drug and alcohol abuse during this period. Further, Afya-mzuri (2012) who quotes DEC statistics, reports that Lusaka Province had the highest number of learners abusing drugs such as alcohol and cannabis. Out of 221 learners who were counselled for drug abuse related problems in 2012, 180 of them came from Lusaka. Media reports have also constantly indicated the issue of rising levels of drug and alcohol abuse among school youths in the country. For instance, speaking during the launch of the anti-drug abuse song and braille brochures for public awareness in Lusaka, on $22^{\text {nd }}$ September 2014, the DEC Deputy Commissioner Mr. Lottie Mpundu noted with concern, the seriousness of the problem of alcohol abuse and youths' addiction to psychotropic substances which required serious attention (Lusakavoice.com., 22/09/14).

This undoubtedly is a source of concern to the citizens, prevention practitioners and government. However, what was not known was what was being done and how it was done regarding drug and 
alcohol abuse prevention education in schools. Hence it was necessary to conduct a study of this nature to establish practices in drug and alcohol abuse prevention education in secondary schools. This article reports on the findings of the study.

\subsection{Statement of the Problem}

Despite the escalating incidences of drug and alcohol abuse among school-going children, little was known concerning prevention practices in Zambia s' secondary schools. The purpose of the study therefore, was to establish practices in drug and alcohol abuse prevention education in selected secondary schools in Zambia.

\subsection{Objective of the Study}

To investigate practices in drug and alcohol abuse prevention education in secondary schools.

\subsection{Research Question}

What were the practices in drug and alcohol abuse prevention education in secondary schools?

\subsection{Significance of the Study}

At a time when there was widespread concern by the citizens, prevention practitioners and government regarding the escalating drug and alcohol abuse among learners in secondary schools, a study of this nature was necessary. Its findings may help school administrators and teachers to plan interventions, promote a drug-free school environment and ultimately improve academic performance in secondary schools. In addition, the study contributed to the body of knowledge on school-based drug prevention education in Zambia.

\subsection{Study Sites}

The study was carried out in twenty (20) secondary schools located in five provinces namely; Lusaka, Copper belt, Southern, Eastern and Luapula.The provinces were chosen based on the prevalence rate of drug trafficking and abuse country-wide. According to Kusanthan (2014) (unpublished)prevalence of drug trafficking and abuse in Zambia is higher in Lusaka (87\%), followed by Copper belt (58\%), Eastern (44\%), Southern (34\%), Muchinga (33\%), Central (26\%) and North-western (20\%)

\subsection{Limitations of the Study}

Due to the sensitive nature of the study, it was difficult to collect information from some target groups who did not want to present data which was considered 'damaging' to their school reputation, as a result, caution must be exercised when generalizing the results of the study. However, the researcher relied on triangulation to validate data.

\section{METHODOLOGY}

The study adopted a descriptive survey research design to collect, analyze and interpret both quantitative and qualitative data. This design was preferred because it allows the researcher to describe the facts and characteristics of a given phenomenon, population, or area of interest (Merriam and Simpson, 1995). A total number of five hundred and fourteen (514) respondents participated in the study. This number included: 400 learners, 91 teachers, 12 head teachers selected form twenty secondary schools in five provinces. In addition, 6 District Education Board Secretaries (DEBS) and 5 Drug Enforcement Commission (DEC) officers located in the selected sites were included because they represented providers or implementers of prevention programmes and activities in schools.

A multi-stage sampling (5 stages) was conducted in which both probability and non-probability procedures were employed. This involved sampling of provinces, districts, schools and finally respondents. For instance, purposive sampling for teachers, head teachers, DEBS and DEC officers, and simple random and systematic random sampling for learners.

Using questionnaires, quantitative data was collected from learners and teachers and analyzed using the Statistical Package for Social Sciences (SPSS) to generate tables, graphs and percentages. Semistructured interview and focus group discussion guides were used to collect qualitative data from Head Teachers, DEBS, DEC officers and learners, which was analyzed using thematic analysis. Thus, major themes were drawn for easy descriptions.

Due to the sensitive nature of the subject, ethical precautions were taken in this study. This included explaining the purpose of the study, giving respondents chance to decide on whether to participate in the study and by keeping their names anonymous. 


\section{FINDINGS AND DISCUSSION}

The study revealed a number of practices that secondary schools performed in drug and alcohol abuse prevention education. These included; teaching of information-based prevention education, the use of external prevention education providers, peer educators and involvement of parents and guardians in prevention service provision. Other practices included evaluation of prevention education activities through role plays, class exercises and question and answer sessions, prevention education was targeted at all leaners in the school with priority given to grades eight and ten learners. Details of the findings of the stated prevention practices are presented and discussed below.

\subsection{Drug and Alcohol Abuse Prevention Education Offered to Learners}

With regard to what they learnt concerning drug and alcohol abuse prevention education, $43.5 \%$ of learners indicated that they learnt factual information regarding types of drugs, causes and their dangerous effects. They further revealed specific topics they learnt such as consequences of abuse, reasons why people use drugs, signs and symptoms of drug abuse and how to avoid drug and alcohol use. Similarly, there were more teachers $89(55.3 \%)$ out of 161 who said that they taught factual information about drug and alcohol abuse. Life skills training at 20 (12.4\%) of 161 respondents, was the least mentioned content material. Details are presented in Figure 1.

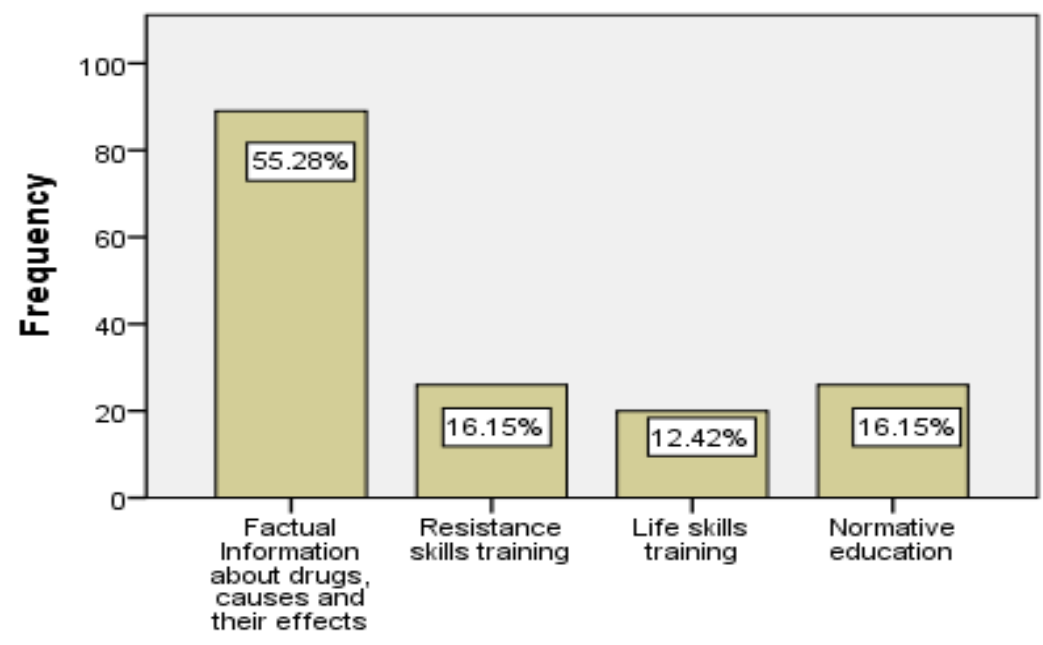

Content of drug prevention education

Figure1. Teachers' responses on the content of drug and alcohol abuse prevention education taught

Most (55.28\%) of the teachers and all Drug Enforcement Commission officers interviewed were in agreement with the learners on the content of drug abuse prevention education. They indicated that they taught more of information-based material than drug refusal skills and normative education.

It was clear from this finding that the drug and alcohol abuse prevention education offered to learners in the selected secondary schools was largely based on knowledge acquisition. This means that learners mainly acquire more of information about drug and alcohol abuse prevention than refusal skills, life skill and normative education. However, the finding contradicts research literature which has revealed that in drug abuse prevention education, focusing on knowledge only is ineffective in preventing drug abuse behaviour among young people(Sower, 1991; Tobler, 1992; Botvin, 1995; The National Crime Prevention Centre, 2009). On the contrary, prevention education programmes with content that focus on social influences' knowledge, drug refusal skills, and life skills have a larger effect size than those which focus on knowledge (Tobler and Stratton, 1997). The researcher is also of the view that teaching of life skills promotes anti-drug and alcohol attitudes and eventually behaviour change. Based on this finding, it is important that teachers and other providers consider to teach content that has the potential to reduce drug and alcohol problem among learners in secondary schools.

\subsection{Providers of Drug And Alcohol Abuse Prevention Education in Schools}

Concerning providers, most learners indicated that apart from their teachers, they also learn about drug abuse prevention from DEC officers and health professionals. Additionally, learners in focus 
group discussions included church pastors, NGOs, head teachers, school matrons and counsellors to the list. Teachers indicated similar responses. All head teachers and DEBS interviewed revealed that they involved other professionals to sensitize learners on drug abuse issues. They cited health workers, Young Women Christian Association (YWCA), Community health And Nutrition, Gender and Education Support 2 (CHANGES 2), Road Transport and Safety Agency (RTSA) and Campaign for Female Education (CAMFED) as some of them.In a face-to-face interview, one Head teacher said:

"We do engage other people, although they come once in a while. For instance from time to time we invite Drug Enforcement Commission officers who came to talk to the children. Just two weeks ago the CAMFED came to talk to girls on many issues including drug and alcohol abuse. So in short we work very well with these organizations."

This finding confirmed that it was common practice to use other professionals in drug and alcohol abuse prevention education in the selected secondary schools.

Indeed the use of professionals is crucial to the success of prevention activities in schools. As noted by Midford et al., (2000) teachers, health professionals, counselors and other prevention practitioners can contribute significantly to the success of school-based prevention interventions. However, what is even more crucial is the training orientation of the provider. Whether it gives him or her the competence and confidence to teach about drug prevention education. In this regard, the study revealed that less than half $(34.4 \%)$ of the 91 teachers confirmed having been trained, while the majority $(65.9 \%)$ were not. In a face to face interview with head teachers and DEBS it was found that most teachers lacked special training in drug abuse prevention. As one head teacher said:

"I think most teachers in this school lack detailed knowledge on issues of drug abuse. They are not trained in most of these cross cutting issues. This is the reason why some of them find difficulties to handle or teach about drugs. Only guidance counsellors can handle such lessons. Unfortunately I only have one trained guidance counsellor"

This showed that although external providers were used, most internal providers lacked special training in field of prevention education. Most teachers in the selected secondary schools were not trained. This situation has the potential to affect the effectiveness of prevention education delivery in secondary schools. It is important that schools must use personnel who are well trained in order to effectively deliver drug and alcohol abuse prevention education in secondary schools.

\subsection{Use of Peer Educators in Prevention Education in Schools}

One of the practices that has gained ground in drug abuse prevention education in recent years is the use of peer educators. This is because, as Midford et al. (2000) pointed out, peer educators serve as potential role models by creating a norm that drug abuse is deviant and by providing alternatives to drug and alcohol abuse. To this effect, the researcher was intrigued to find out whether secondary schools used peer educators in prevention education activities.

Findings from learners and teachers confirmed the use of selected learners in the school to provide drug and alcohol abuse prevention education to fellow learners. In a face to face interview with some head teachers, they indicated that all learners who were in leadership in the school were considered as peer educators because they had a responsibility to guide other learners. However, they added that most of them were not trained in drug abuse prevention. One head teacher lamented that:

"All learners in leadership in this school are considered as peer educators because they are expected to guide and counsel their fellow learners, I mean the prefects, learners council members, and Safe Club members. But the problem is that most of them are not trained. We are very thankful to CAMFED who trained about 30 girls two years ago but some of them have since left the school."

From these findings one can deduce that although peer educators were used in most secondary schoolsthey lacked training in drug and alcohol abuse prevention education and facilitation skills. This situation affected prevention education negatively, in that peer educators lacked basic knowledge and facilitation skills to carry out their function.

Use of trained peer educators in drug abuse prevention in the school can greatly enhance prevention programmes. As rightly argued by Coggans and Watson (1995) carefully selected, well supported and trained peer educators have a great impact in the reduction or delay of drug and alcohol abuse 
behaviours. When well directed and mentored their influence can produce amazing results in drug abuse prevention in schools. Secondary school administrators are therefore, encouraged to make use of trained peer educators who can work together with teachers to prevent drug and alcohol abuse in schools.

\subsection{Involvement of Family (Parents and Guardians) in Drug and Alcohol Abuse Prevention}

On the question of involvement of family members as partners in prevention efforts, it was found that the majority $(67 \%)$ of the teachers indicated that they sometimes involved parents. Figure 2 shows the distribution of responses.

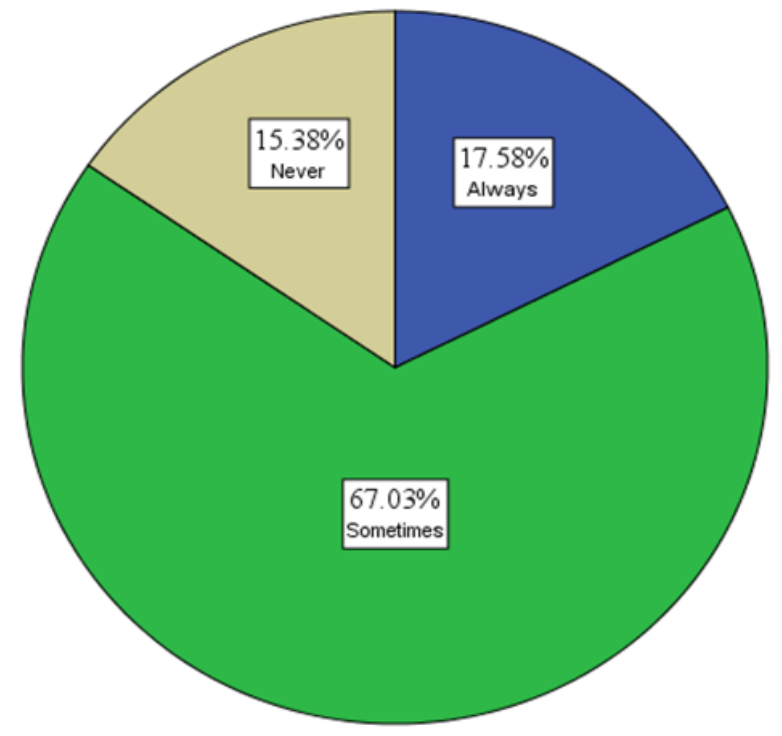

Figure2. Whether parents or guardians were involved in drug and alcohol abuse prevention in the school

Similarly, interviews with teachers and DEBS confirmed involvement of parents and guardians. Surprisingly, they further explained that parents were only involved depending on the gravity of the cases they were handling. It can be deduced from this response that it was not always that they involved parents or guardians. In their explanation, head teachers and DEBs said that the involvement of parents was done by calling them to discuss their children's behaviour in relation to abuse of drugs or alcohol. This was only done in special circumstances. This finding, regarding involvement of parents is encouraging, and is consistent with that of Dusenbury and Falco (1995) who found that involvement of family members, enhanced school-based prevention efforts and was an effective way of reducing drug use among young people. However, parents need to be fully involved in prevention education as well. The role of parents and guardians in this matter cannot be overemphasized. They can help in the enforcement of school policies as well as sensitizing their children on the dangers of drug and alcohol abuse. Learners are still under the influence of their parents, hence partnership between the school and parents can be very vital in bringing about desirable behaviour change among learners. Secondary schools in Zambia ought to seize the opportunity to utilize parents in prevention education if they are to arrest the escalating levels of drug and alcohol abuse among learners.

\subsection{Monitoring and Evaluation of Drug and Alcohol Abuse Prevention Activities in the School}

With regard to evaluation of the immediate impact of drug and alcohol abuse prevention lessons or activities on learners, it was found that teachers used role play, class exercise and demonstrations. Interestingly, all the DEC officers interviewed mentioned only one method used to evaluate the immediate impact of their drug lesson or activity, and that was through a question and answer segment (mainly oral questions) conducted at the end of the lesson or activity. This means that when questions are correctly answered, it was a clear sign to them that learning had taken place.

An analysis of these findings showed that most teachers were limited to the use of role plays and class exercises (written questions on drug topics) to evaluate the immediate impact of their drug prevention lesson and activity while DEC officers largely use question and answer method. In substantiating their statements some DEC officers explained that it was difficult to do any other form of evaluation due to limited time they were given to interact with learners in schools. 
Generally, the study revealed that there were very limited ways of monitoring and evaluating prevention education activities by both internal and external providers in the selected secondary schools. This obviously affects quality delivery and also the outcome among learners. However, effective evaluation of outcome is very important. The practice of evaluating drug and alcohol abuse prevention education activities is also advocated by UNODC/WHO (2006), who argue that, it enables providers to take a critical look at whether prevention activities are producing intended outcomes or not and how they can be improved.

\subsection{Target Groups in Drug and Alcohol Abuse Prevention Education}

Regarding the target of prevention education activities, almost all (97.8\%) teachers said they targeted all leaners in the school. Head teachers and DEBS were in agreement with teachers views. However, in relation to the grade levels, most targeted or priority grades so to speak, head teachers emphasized that special consideration was given to grades eight and ten learners while most teachers maintained that all grades were equally targeted. Head teachers argued that being new in the school the learners in the mentioned grades needed special protection from undesirable peer pressure from older learners. In emphasis, one head teacher of a boarding school argued:

"Our grade eights need more guidance because all of them are new to the school environment. We need to teach them, for example how to identify bad influence and so on and so forth. Equally half of the grade tens may be new to the school as well. So really, prevention education is very necessary to them at this point"

These contradictory views could have been influence by different perspectives in the implementation strategies held by head teachers and the teachers regarding priority targets. Similar findings were reported by Morojele et al (2008) who found that organizations that provided school-based substance abuse prevention education in Cape Town South Africa, targeted various grades ranging from standard 4 to standard 10. Findings from DEC officers indicated that they did not only target learners, but also teachers and other workers in the school.

Findings from teachers, head teachers and DEBS seem to suggest that learners were the only target of prevention education in the schools. This finding was contrary to NIDA (1997) who stated that prevention interventions must target not only individuals (learners) but also families, work groups, the worksite, neighborhoods and the entire communities. It is important that school-based prevention education activities must target not only learners but also teachers, workers, parents and all visitors who come to the school, as it will create a supportive school environment that will reduce drug and alcohol use by learners. This is supported by NIDA (1997) who pointed out that, prevention education should be tailored to address risks specific to population or audience characteristics.

\subsection{Timing of Interventions for Drug and Alcohol Prevention}

Regarding timing of interventions, findings showed that majority (61.5\%) of learners first learnt about drug abuse prevention, in secondary school, in grade eight. In a face to face interview with head teachers, it was revealed that prevention education was introduced early in grade eight. To emphasize this point, one head teacher said:

"It is part of the school orientation programme for grade eight learners in this school. We conduct this in the first term every year."

The findings from head teachers corroborate those of learners. An analysis of these findings clearly indicate that learners are exposed to prevention education early enough in their secondary school life. This is consistent with the recommendation made by Otieno (2009) who conducted a study in Kisumu town, Kenya, that there was need for early intervention that targets pre-secondary and early secondary school learners because these learners were a high-risk group. As rightly stated by Tobler et al (2000) interventions that were implemented when children were in early high school years were more likely to be effective. This is because this is when they are developing skills of life. The researcher encourages secondary school authorities to conduct early intervention programmes in their school if they are to successfully reduce drug and alcohol use among learners.

\section{CONCLUSIONS AND RECOMMENDATIONS}

In line with the study objective on the practices in drug and alcohol abuse prevention education in the selected secondary schools, the researcher concludes that the drug and alcohol abuse prevention 
education offered to learners in the selected secondary schools was largely based on knowledge acquisition than refusal and life skills training. This finding is not in line with evidence-based practices ((Tobler and Stratton, 1997; The National Crime Prevention Centre, 2009). The study has also shown that teachers and other external provider, peer educators and parents or guardians were involved in the provision of drug and alcohol abuse prevention education in the selected schools. However, most peer educators and teachers lacked training in drug and alcohol abuse prevention education and facilitation skills. In addition, parents were only used when it came to sorting out disciplinary issues resulting from abrogation of school rules by their children and not in prevention education. Furthermore, the study concludes that there were very limited methods used for evaluating the impact of prevention activities being practiced by most providers, with teachers using mainly role play and written exercise, while DEC officers relied entirely on question and answer method after a lecture presentation. This scenario may have contributed to the escalating levels of drug and alcohol use among learners.

As regard targeting of prevention education in schools, the study concludes that the main target population were learners at all grade levels. However, transitional grades, that is, grade 8 and grade 10 , were given priority. In terms of timing of intervention implementation, learners were exposed to prevention education early enough (grade 8) in their secondary school life. Based on the study findings, the following recommendations are made:

- Providers of drug and alcohol abuse preventive education should teach content that has the potential to reduce abuse by learners in the school,Such as drug refusal skills in combination with social life skills training as it is more likely to lead to behaviour change.

- Teachers should receive special training in drug and alcohol abuse preventive education to ensure effective delivery of drug and alcohol abuse related issues. In addition, School administrators should use trained peer educators who can work together with teachers and other providers to educate learners. Use of carefully selected, well supported and trained peer educators has a great impact in the reduction or delay of drug and alcohol abuse behaviours (Coggans and Watson, 1995).

- School based drug and alcohol abuse prevention education should involve parents (family). Since parents still have influence over their children, they can implement various measures in a home that may reduce the likelihood that their children will use alcohol or other drugs in school or at home (Morojele et al., (2009). Indeed as UNODC (2004:12) stated, "effective inclusion of parents and guardians will increase the success of achieving the desired effect in the primary target group."

- Prevention activities should be monitored and evaluated using a variety of evaluation methods. Both impact and outcome evaluation should be conducted in order to gauge progress in prevention efforts. Evaluation of prevention activities enables providers to take a critical look at whether intended outcomes are achieved or not and how they can be improved.

- The practice of providing early intervention should be encouraged. This is because there is evidence that the younger the adolescent starts using drugs the more he or she is likely to develop drug use related problems (UNODC, 2016).

\section{REFERENCES}

Afya-Mzuri(2012). Change for Health. Alcohol and Drugs. Lusaka

Coggans, N. and Watson, A. (1995). Drug education: Approaches, effectiveness and delivery, Drugs Education, prevention and policy 2 (3), 211-24

DEC, (2012). Annual Report, 2011-2012

DEC, (2014). Speech by Commissioner, for Drug Enforcement Commission presented at the 2014 World Anti-drug Day Cerebration, Lusaka Zambia.

Dusenbury, L. and Falco, M. (1995). Eleven Components of Effective Drug Abuse Prevention Curricula. Journal of Health, Vol. 65. No 10, 420-425

Lusakavoice.com., 22/09/14

Merriam, S.B. and Simpson, E.L. (1995). A Guide to Research for Educators and Trainers of Adults ( $\left.2^{\text {nd }} E d.\right)$, Malabar Florida: Krieger Publishing Company. 
Midford, R., Lenton, S. and Hancock, L. (2000). A critical Review and Analysis: Cannabis Education in Schools. A Report for the NSW Department of Education and Training, Perth: Cutin University of Technology, (Retrieved 23/11/14).

Morojele, N., Knott, R., Hyburg, H., and Finkelstein, (2008). Audit of school-based substance abuse programmes in Cape Town. SA Health info.

National Crime Prevention Centre, (2009).School-based Drug Abuse Prevention: Promising and Successful programmes,(Online) Available: http://www.publicsafety.gc.ca/res/cp/res/2009-01grg-abs-eng.aspx (February 11, 2014)

National Institute on Drug Abuse, (1997). Preventing Drug Use among Children and Adolescents. A Research-based Guide. Rockville: NIH Publication No. 97-4212.

Tobler, N. S. (1992).Drug prevention programs can work: research findings, Journal of Addictive Diseases 11: 1-28.

Tobler, N.S. and Stratton, H.H. (1997). Effectiveness of School-based Drug Prevention Programmes: A Meta-Analysis of the Research, The Journal of primary prevention 18 (10), 71-128.

Tobler, N. S. (2000). Lessons learned, The Journal of Primary Prevention 20: 261-274.

UNODC/WHO, (2006). Monitoring and Evaluating Youth Substance Abuse Prevention Programmes. Vienna. UN Publication.

UNODC, (2016). Facts for Policy Makers, (Online) Available: www.unodc.org/listen first. (June 30, 2016)

\section{AUTHORS' BIOGRAPHY}

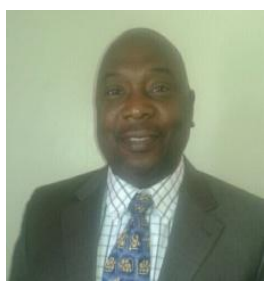

Isaac Masiye, is an Educational Psychologist and a $\mathrm{PhD}$ Candidate in the School of Education, Department of Educational Psychology, Sociology and Special Education (EPSSE) at the University of Zambia. He is currently serving as Deputy National Coordinator in the Education and Counselling Department of the Drug Enforcement Commission - Zambia. He has over 15 years' experience in the field of drug and substance abuse prevention education and counselling. His $\mathrm{PhD}$ thesis is about Drug and Alcohol Abuse Prevention Education Practices and Policies in Secondary schools in Zambia. He has published two articles on drug and alcohol abuse preventionin the International Journal of Multidisciplinary Research and Development(Online e-ISSN: 2349-4182). Isaac has also participated in various National and International fora on strategic planning of drug use prevention programmes. He is currently the African Union Commission (AUC) - Drug demand Reduction Focal point for Zambia.

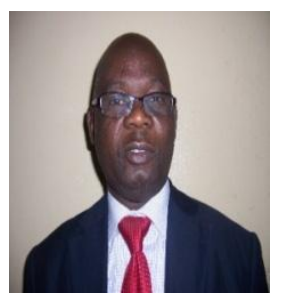

Dr. Daniel Ndhlovu, is a Senior lecturer in the Department of Educational Psychology, Sociology and Special Education at the University of Zambia. He holds a doctoral degree in Special Education, Mastersdegree in Education and Bachelor's degree in Special Education from the University of Zambia. In addition to lecturing, he has held senior administrative positions at the University of Zambia which includes Assistant Dean Postgraduate in the School of Education and Assistant Director Postgraduate in the Institute of Distance Education. Daniel has 29 years teaching and lecturing experience at secondary school, tertiary and university levels of education. He has done numerous research activities and publications in local and international refereed journals. His latest publication is Teaching materials in phonology for pupils with hard of hearing in selected schools of Chongwe District, Lusaka province, Zambia authored by RoseChikopela and Daniel Ndhlovu. International Journal of Multidisciplinary Research and DevelopmentOnline ISSN: 2349-4182. 